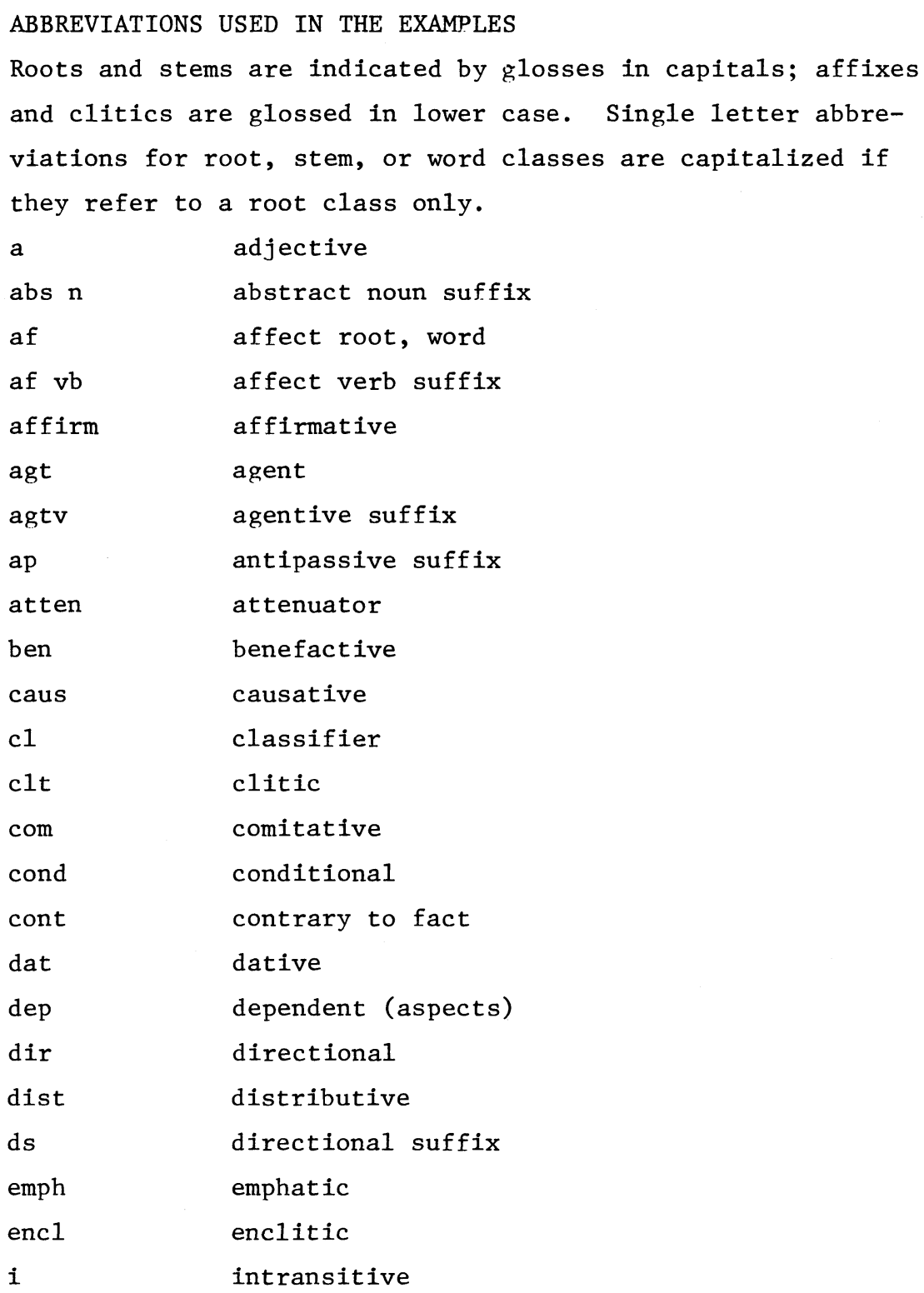

a

abs $n$

af

af $\mathrm{vb}$

affirm

agt

agtv

ap

atten

ben

caus

c1

c1t

com

cond

cont

dat

dep

dir

dist

ds

emph

enc1

i

adjective

abstract noun suffix

affect root, word

affect verb suffix

affirmative

agent

agentive suffix

antipassive suffix

attenuator

benefactive

causative

classifier

clitic

comitative

conditional

contrary to fact

dative

dependent (aspects)

directional

distributive

directional suffix

emphatic

enclitic

intransitive 


\section{$x$ ABBREVIATIONS USED IN THE EXAMPLES}

\begin{tabular}{|c|c|}
\hline imp & imperative \\
\hline inf & infinitive \\
\hline inj & interjection \\
\hline inst & instrument \\
\hline int & interrogative \\
\hline intens & intensifier \\
\hline LOC PRED & locative/existential predicate \\
\hline $\mathrm{n}$ & noun \\
\hline$n \rightarrow a d j$ & noun to adjective derivational suffix \\
\hline$n \rightarrow t$ & noun to transitive derivational suffix \\
\hline neg & negative \\
\hline ord num & ordina1 number \\
\hline$P$ & positional \\
\hline $\mathrm{p} \rightarrow \mathrm{i}$ & positional to intransitive derivational suffix \\
\hline $\mathrm{p} \rightarrow \mathrm{t}$ & positional to transitive derivational suffix \\
\hline part & participle \\
\hline pas & passive \\
\hline pas? & $\begin{array}{l}\emptyset \text { passive or agentless transitive, depending } \\
\text { on analysis }\end{array}$ \\
\hline pat & patient \\
\hline perf & perfective \\
\hline $\mathrm{p} 1$ & plural \\
\hline pos & possessive \\
\hline pos adj & positional adjective \\
\hline pot & potential \\
\hline proc & processive \\
\hline proc imp & processive imperative \\
\hline proc pas & processive passive \\
\hline prog & progressive \\
\hline rec & recent past \\
\hline ref1 & reflexive \\
\hline re1 & relative marker \\
\hline
\end{tabular}




\section{ABBREVIATIONS USED IN THE EXAMPLES $x i$}

$\mathrm{RN}$

spec term

1s

$2 s$

$3 s$

$1 \mathrm{p}$

$1 \mathrm{p}$ ex

$1 p$ in

$2 \mathrm{p}$

$3 \mathrm{p}$

1sA, etc.

1sE, etc.

relational noun

specific termination of action derivational suffix

transitive

first person singular

second person singular

third person singular

first person plural

first person plural exclusive

first person plural inclusive

second person plural

third person plural

1s emph, etc. first person singular emphatic marker, etc.

Note: Person prefixes are marker $1,2,3 \mathrm{~s} / \mathrm{p}$ although the interpretation fepends on the enclitics. Enclitics are also marked 1, $2 \mathrm{~s} / \mathrm{p}$. Absolutive/ergative distinctions are marked on verbs. Nonverbal predicates are marked absolutive to distinguish the markers from the enclitics for person, which are contiguous. Noun possessive prefixes are not marked 'ergative' although the prefixes for possession are the same as the ergative markers.

Morphemes in the examples and glosses are separated by a -. A slash within a gloss is used to further qualify the gloss; e.g. RN/in means 'relational noun meaning in'. 
THIS PAGE INTENTIONALLY LEFT BLANK 